\title{
RESULTS OF USING 3-D SIMULATION METHODS IN TREATMENT OF MIDFACIAL FRACTURES
}

\author{
Anton Khudyk $\boldsymbol{k}^{1}$, Sergey Grigorov ${ }^{2}$ \\ ${ }^{1}$ Department of Surgical Dentistry and Maxillofacial Surgery, Kharkiv National Medical University, Kharkiv, Ukraine \\ vodoo999@gmail.com \\ ORCID: https://orcid.org/0000-0002-9015-2301 \\ ${ }^{2}$ Department of Surgical Dentistry and Maxillofacial Surgery, Kharkiv National Medical University, Kharkiv, Ukraine \\ grigorovserg@yahoo.com \\ ORCID: https://orcid.org/0000-0001-9527-8408
}

ARTICLE INFO

Article history:

Received date 30.03 .2021

Accepted date 27.04.2021

Published date 30.04 .2021

Section:

Practical medicine

Dol

10.21303/2313-8416.2021.001727

KEYWORDS

traumatic fractures of the middle zone of the face

bone metal osteosynthesis

open reposition

itanium miniplates

intraoral access

CAD/CAM systems

computed tomography

SLM technology

3D simulated titanium mini-plates/grids

\section{A BSTRACT}

The article publishes the results of treatment of 27 patients with fractures of the face middle area, of which 14 used standard titanium mini-plates to reposition the fragments, and 13 - individual 3D simulated titanium mini-plates/grids. Before and after treatment, its effectiveness was assessed by the values of the displacements of bone fragments and the index of the visual-analog scale, which allows determining the functional and cosmetic effect of the surgery. It was found that the use of individual 3D simulated titanium mini-plates/grids allowed obtaining in $85 \%$ of patients displacements not exceeding $3 \mathrm{~mm}$. In $72 \%$ of patients in whom standard titanium mini-plates were used, the displacement after surgery was $3.1-6 \mathrm{~mm}$, which is significantly greater than in the group with individual modeling of structures.

On the 7th day after surgery in the first group (treatment with standard mini-plates), the index on the visual-analog scale was $11(7 ; 13)$, which was significantly $(p=0.00147)$ less than before surgery. In the second group (treatment using individual 3D simulated titanium miniplates/grids) the index on the visual analog scale was $4(6 ; 8)$ points, which was significantly $(Z=3.3 ; p=0.00098)$ less than before surgery. Comparison of the visual-analog scale of the first and second groups on the $7^{\text {th }}$ day after surgery revealed the presence of significant $(U=2.47$; $p=0.013$ ) differences. The obtained results testify to the greater efficiency of individual 3D modeled titanium mini-plates/grids in comparison with standard titanium mini-plates.

The object of the research: fractures of the middle area of the face. Comparison of the visual-analog scale of the first and second groups on the $7^{\text {th }}$ day after surgery revealed the presence of significant $(U=2.47 ; p=0.013)$ differences.

Investigated problem: the comparative evaluation of the effectiveness of the middle area of the face fractures treatment using individual 3D simulated titanium mini-plates/grids and standard titanium mini-plates.

The main scientific results: Optimizing the treatment of fractures of the face middle area will help to achieve good cosmetic and functional results.

The area of practical use of the research results: Department of Surgical Dentistry and Maxillofacial Surgery.

Innovative technological product: The proposed technique using individual 3D-simulated titanium miniplates will help to optimize the treatment of patients with traumatic fractures of the face middle area.

Scope of the innovative technological product: Clinical practice.

(C) The Author(s) 2021. This is an open access article under the Creative Commons CC BY license

\section{Introduction}

\section{1. The object of the research}

Fractures of the middle area of the face.

\section{2. Problem description}

According to a number of authors, the frequency of injuries to the middle area of the face has been steadily increasing in recent years. This is facilitated by high urbanization of the population, increasing technical equipment and intensification of production, increasing transport speeds, improving diagnostic methods $[1,2]$. 
Currently, in maxillofacial traumatology the term "fractures of the middle zone" of the face, more precisely, the upper part of the facial skull is increasingly used. The face middle area is limited at the top by the upper orbital line, and below - by the line of closure of the dentition, including in this area the nasal bones, orbital walls, cheekbones and zygomatic arches, the upper jaw [3].

The bones of this zone have mainly a vertical type of structure of spongy trabeculae and the presence of four buttresses $[3,4]$.

The bones of the middle zone of the face have an arched structure; there is an alternation of buttresses with places of weak resistance, which include the lacrimal bone, the lattice bone plate, anterior, posterior and medial jaw walls, the orbit (namely, almost the walls of the maxillary sinuses) and the pterygoid plate. [3].

Thus, the anatomical structure, on the one hand, provides an intimate connection of the bones of the face middle area, on the other - is a factor determining the direction of the fracture. The nature of the damage, the shape and direction of the fracture are not accidental, but due to the mechanism of action of the impact force and depend not only on the magnitude and direction of the impact force, size and shape of the object, weapon, but also on properties related to bone architecture and distribution of force vectors acting on impact on specific bone elements [4-6].

Since buttresses and so-called places of weak resistance are located in relation to each other in different planes, it is natural that the effective force of impact to one of them will be directed perpendicularly, to another - parallel, and to the third -- at an angle and, therefore, will cause quite diverse and numerous fractures of the middle zone of the face [4-7].

Among the pathologies that cause the development of facial defects of the facial skull, a significant place is occupied by fragmentary traumatic fractures, bone tumors and chronic purulent-inflammatory diseases [8].

Due to the development of medical technologies and the emergence of new materials, a large number of surgical methods to eliminate bone defects have been developed, the vast majority of which involve the use of auto- and allografts $[9,10]$.

\section{3. Suggested solution to the problem}

The main surgical methods for the treatment of the jaws fractures are bone suture, osteosynthesis using Kirchner needles, osteosynthesis using bone structures in the form of mini-plates and screws, mainly titanium $[11,12]$. The most common modern method of fixation of fragments in fractures of the maxillofacial area is bone osteosynthesis using standard mini-plates after open repositioning of fragments [13-15]. This method reduces the duration of immobilization of the jaws, which in turn restores the function of chewing at an early stage and reduces the time of rehabilitation of patients. The disadvantage of this method is the inability to achieve an accurate and complete fit of the plates in the fracture area, especially in multi-fragment injuries, which is due to the anatomical structure of the bones of the facial skull. Another disadvantage of this method is the possible trauma of the cortical layer of the fixing elements due to the uneven load distribution with incomplete fit of the mini-plate. The use of standard titanium mini-plates prolongs the time of surgery and increases intraoperative tissue trauma, and also does not always provide reliable immobilization of fragments due to the small number of fixation points of mini-plates [16-18].

A more advanced method of osteosynthesis surgery for the jaws fractures is the use of 3D-simulated titanium mini-plates [19].

Also a method of treatment of mandibular fractures using CAD/CAM systems (Computer-Aided Design/Computer-Aided Manufacture) based on computed tomography was developed. These systems allow to create a model of fracture and determine the optimal ways to eliminate it [20-22].

Thus, despite the large number of proposed methods of osteosynthesis, the search for the most effective method of prosthetics of bone defects and reliable fixation of bone fragments is relevant due to their clinical and anatomical diversity and the likelihood of postoperative complications.

The aim of the study was to compare the results of treatment of fractures of the face middle area by metal osteosynthesis methods using individual 3D simulated titanium mini-plates/grids and standard titanium mini-plates. 


\section{Materials and methods}

On the basis of the Department of Surgical Dentistry and Maxillofacial Surgery of Kharkiv National Medical University at the Department of Head and Neck Surgery of the Municipal Non-Commercial Enterprise of Kharkiv Regional Council "Regional Clinical Hospital", (Kharkiv, Ukraine) for the period from January 1, 2018 to December 31, 2020 twenty-seven patients with traumatic fractures of the bones of the face middle area received treatment. Those patients were performed repositioning of bone fragments with subsequent fixation using methods of bone metal osteosynthesis.

Informed consent to participate in the study was obtained from all patients. The methods used in this study were agreed and approved by the Ethics Commission Board of Kharkiv National Medical University No. 6 from 04.10.2017, in accordance with the Declaration of Helsinki (1975).

Examination of patients during hospitalization included: general clinical blood and urine tests, biochemical blood tests, electrocardiography, cone-beam computed tomography (CBCT).

A visual analog scale (VAS) was used to assess the severity of clinical manifestations of traumatic injuries before treatment, as well as the course and results of treatment [23].

An important index that determines the further tactics of treatment is the amount of displacement of bone fragments. For the convenience of presenting information, a scoring scale was introduced, according to which: 0 points - no displace, 1 point - displace from 1 to $3 \mathrm{~mm}$, 2 points $-3.1-6 \mathrm{~mm}, 3$ points $-6.1-9 \mathrm{~mm}, 4$ points $-9.1-12 \mathrm{~mm} ; 5$ points $-12.1-15 \mathrm{~mm}$; 6 points more than $15 \mathrm{~mm}$.

Patients were offered two methods of fracture treatment, by metal osteosynthesis - using standard titanium mini-plates and using individual 3-D simulated titanium mini-grids. After a thorough explanation of all the advantages and disadvantages of each method, patients chose the method of treatment with their voluntary consent. The first group consisted of 14 patients who underwent repositioning with fixation of fragments with standard titanium mini-plates. The second group consisted of 13 patients for whom the fixation of the repositioned bone fragments was performed by individual 3-D simulated titanium mini-grids. In the first group there were $11(79 \pm 10.9) \%$ men and $3(21 \pm 10.9) \%$ women. In the second group, all patients were male. The mean age of patients in the first group was (31.9 \pm 6.8$)$ years with a range of 19 to 43 years, the mean age of patients in the second group was (30.2 \pm 9.6$)$ years with a range of 19 to 54 years. Thus, all patients were of working age.

The results of the study were processed using the methods of descriptive statistics, non-parametric $\chi^{2}$ criteria of Pearson and Mann-Whitney. In cases of significant variance of indices, the medians (Me) and quartiles were calculated (25\%; $75 \%)$.

\section{Research results and their discussion}

The distribution of patients in the study groups by the term of treatment is given in Table $\mathbf{1}$.

Table 1

Distribution of patients according to the term of treatment, (\%)

\begin{tabular}{ccccc}
\hline \multirow{2}{*}{ Group } & \multicolumn{4}{c}{ Time to see a doctor, day } \\
\cline { 2 - 5 } & $\mathbf{0}$ & $\mathbf{1 - 3}$ & $\mathbf{4 - 7}$ & More than 7 \\
\hline $1(n=14)$ & $5(36 \pm 12.6)$ & $5(36 \pm 12.6)$ & $2(14 \pm 9.3)$ & $2(14 \pm 9.3)$ \\
$2(n=13)$ & $1(8.0 \pm 7.5)$ & $1(8.0 \pm 7.5)$ & $2(15 \pm 9.9)$ & $9(69 \pm 12.8)$
\end{tabular}

According to Table 1, it can be noted that a significant $(p<0.05)$ majority of patients of the first group started treatment within 1-7 days. The majority $(p<0.05)$ of patients of the second group started treatment within 7 days of injury.

$12(86 \pm 9.3) \%$ of patients of the first group had a small fragmentary fracture, $2(14 \pm 9.3) \%$ had a large fragmentary fracture. The second group also had $12(92 \pm 7.5) \%$ of patients with small fragments and $1(8.0 \pm 7.5) \%$ with large fragments. It can be noted that most patients of both groups had a small fragmentary fracture.

Table 2 shows the distribution of patients on the side of the injury localization, the analysis of which showed that the majority of patients of both groups $(p<0.05)$ had a fracture on one side. 
Table 2

Distribution of patients by the location of the injury, (\%)

\begin{tabular}{cccc}
\hline Group & From the right side & From the left side & From both sides \\
\hline $1(n=14)$ & $6(43 \pm 13.2)$ & $5(36 \pm 12.6)$ & $3(21 \pm 10.9)$ \\
$2(n=13)$ & $6(46 \pm 13.8)$ & $5(38 \pm 13.5)$ & $2(15 \pm 9.9)$
\end{tabular}

According to the location of the fracture, patients of the first group were distributed as follows: in $1(7.1 \pm 6.8) \%$ of patients there was a fracture of the temporomandibular complex (TMC) without damage to the walls of the maxillary sinus, in $9(64 \pm 12.8) \%$ - combined fractures of the TMC with damage to the walls of the maxillary sinus, Le-Fort fractures or bilateral - in $4(29 \pm 12.1) \%$ of patients. In the second group in $6(46 \pm 13.8) \%$ of cases there was a fracture of the TMC without damage to the walls of the maxillary sinus, in $5(38 \pm 13.5) \%$ - combined fractures of the TMC with damage to the walls of the maxillary sinus, in $2(16 \pm 10.2) \%$ of cases - Le Fort type fractures (bilateral). There were no significant differences between the groups in the frequency of occurrence of different fracture sites.

The average bed-day in patients of the first group equaled (13.3 \pm 5.6$)$ days with a range of 4 to 26 days. It was $(11.3 \pm 4.8)$ days with a range of 3 to 20 days in patients of the second group. No significant differences in the length of stay in hospital between patients of the study groups were found. Prolonged stay of some patients in the hospital was due to the presence of concomitant injuries.

An important characteristic that allows the researchers to assess the severity of the injury is the number of fractures in a particular patient (Table 3).

Table 3

Distribution of patients by the number of fracture sites, (\%)

\begin{tabular}{ccccc}
\hline Group & In one place & In two places & In three places & In four places \\
\hline $1(n=14)$ & $2(15 \pm 9.5)$ & 0 & $3(21 \pm 10.9)$ & $9(64 \pm 12.8)$ \\
$2(n=13)$ & 0 & $1(8.0 \pm 7.5)$ & $3(23 \pm 11.7)$ & $9(69 \pm 12.8)$
\end{tabular}

According to Table 3, it can be noted that in a significant $(p<0.05)$ majority $(64-69 \%)$ of patients in the study group fractures were localized in 3-4 places, namely, fractures with complete separation of the cheekbone - in the literature known as "tripod fracture" or "tetrapod fracture".

Using the results of $\mathrm{CBCT}$, the amount of displacement of bone fragments before treatment was determined. Table 4 shows the distribution of patients on the points of the interval scale for estimating the amount of displacement of bone fragments.

Table 4

Distribution of patients in the study group according to the points of the interval scale of displacement of bone fragments before treatment, (\%)

\begin{tabular}{ccccccc}
\hline \multirow{2}{*}{ Groups } & \multicolumn{5}{c}{ Displacements, points } \\
\cline { 2 - 6 } & $\mathbf{1}$ & $\mathbf{2}$ & $\mathbf{3}$ & $\mathbf{4}$ & $\mathbf{5}$ \\
\hline $1(n=14)$ & 0 & $1(7.0 \pm 6.8)$ & $3(21 \pm 10.9)$ & $5(36 \pm 12.6)$ & $3(21 \pm 10.9)$ & $2(15 \pm 9.5)$ \\
$2(n=13)$ & 0 & $1(8.0 \pm 7.5)$ & $3(23 \pm 11.7)$ & $5(38 \pm 13.5)$ & $2(16 \pm 10.2)$ & $2(16 \pm 10.2)$
\end{tabular}

According to Table 4 it can be noted that in a significant $(p<0.05)$ majority of patients $(71-$ $77 \%$ ) of both groups the displacement of bone fragments corresponded to 3-6 points (9-15 mm).

Evaluation of the significance of the displacement, which can be cosmetic (causes aesthetic disorders), functional (causes dysfunction), and mixed (cosmetic and functional), showed that a purely cosmetic value of the displacement was in $2(14 \pm 9.3) \%$ of patients of the first group and in $3(23 \pm 11.7) \%$ of patients of the second group, mixed - in $12(86 \pm 9.3) \%$ of patients of the first group and in $10(77 \pm 11.7) \%$ - in the second group. It can be noted that in the vast majority of patients the shift in significance was both cosmetic and functional.

In some patients, in addition to fractures of the face middle area other complications were observed: fractures of the mandible - in $1(8.0 \pm 7.5) \%$ of patients in the second group; fractures of 
the nasal bones - in $5(36 \pm 12.8) \%$ of patients of the first group and $5(38 \pm 13.5) \%$ of patients of the second group; combined fractures of the mandible and nasal bones - in $2(16 \pm 10.2) \%$ of patients of the first group.

Paresthesia in the occipital region was observed in all patients of both groups. Hemosinus on $1 / 3$ of the sinus was observed in $1(7.0 \pm 6.8) \%$ of the patient of the first group and $4(31 \pm 12.8) \%$ of the second; $2 / 3$ of the sinuses - in $3(21 \pm 10.9) \%$ of patients of the first group and $2(16 \pm 10.2) \%-$ of the second; total - in $9(64 \pm 12.8) \%$ of patients of the first group in $5(38 \pm 13.5) \%$ - the second. Thus, in a significant $(p<0.05)$ majority of patients in both groups there was hemosinus of varying degrees.

After treatment, its effectiveness was evaluated, which was determined by anatomical and functional-cosmetic effectiveness. Anatomical efficiency was evaluated by the value of the remaining displacement of the fragments, functional and cosmetic - by the values of the VAS index.

Table 5 shows the distribution of patients according to the scores of the fragments displacement that remained after surgery.

\section{Table 5}

Distribution of patients in the study group on the points of the interval scale of the bone fragments displacement after treatment, $(\%)$

\begin{tabular}{cccccc}
\hline \multirow{2}{*}{ Groups } & \multicolumn{4}{c}{ Displacement, points } \\
\cline { 2 - 5 } & $\mathbf{0}$ & $\mathbf{1}$ & $\mathbf{2}$ & $\mathbf{3}$ \\
\hline $1(n=14)$ & 0 & $1(7.0 \pm 6.8)$ & $10(72 \pm 12)$ & $3(21 \pm 10.9)$ \\
$2(n=13)$ & $2(15 \pm 9.9)$ & $9(69 \pm 12.8)^{*}$ & $2(15 \pm 9.9)^{*}$ & 0
\end{tabular}

Note: * differences in the frequency of occurrence of the corresponding offset between the studied groups are significant $(p<0.05)$

According to Table 5 it can be noted that $85 \%$ of patients in the second group after surgery had no displacement, or it was 1-3 mm. In $72 \%$ of patients in the first group, the displacement was 3.1-6 mm, namely, it was greater than in the second group in a significant $(p<0.05)$ majority of patients.

Before treatment, the VAS score for the patients in the first group was $16(13 ; 21)$, in the second - $14(12 ; 19)$. There were no significant differences between the VAS groups before treatment. Also, the VAS evaluation was performed on the 7th day after surgery. In the first group, the VAS index equaled $11(7 ; 13)$, which was significantly $(p=0.00147)$ less than before surgery. In the second group, the VAS index was $4(6 ; 8)$ points, which was significantly $(p=0.00098)$ less than before surgery. Comparison of VAS indices of the first and second groups on the 7th day after surgery revealed the presence of significant $(p=0.013)$ differences. VAS in the second group was significantly less than in the first group, which indicated the greater efficiency of individual 3D simulated titanium mini-plates/grids compared to standard titanium mini-plates.

To illustrate the results of using the two described methods of treatment, clinical examples are given.

Patient V., 43 years old, turned to the Department of Head and Neck Surgery of the Municipal Non-Commercial Enterprise of Kharkiv Regional Council "Regional Clinical Hospital" with complaints of pain in the projection of the upper jaw, occlusion disorders, facial configuration disorders, nosebleeds after injury, numbness in the left and right maxillary areas, deterioration of the general condition. According to the patient, he was injured as a result of beating by an unknown person (domestic injury). After the injury, he appealed for medical help from the Head and Neck Surgery Department within 6 hours.

During the examination the patient underwent CBCT (Fig. 1, a, b), the results of which were diagnosed as: "Traumatic fracture of the upper jaw type Le-Fort I. Traumatic fracture of the right zygomatico-orbital without significant displacement of fragments. Traumatic fracture of the left zygomatico-orbital with displacement of fragments. Bilateral hemosinus".

According to the CBCT, the displacement of the fragments was up to $6.54 \mathrm{~mm}$. The patient was diagnosed with a small fracture of the wall of the left maxillary sinus. The patient underwent left maxillary sinusectomy with repositioning of fragments of the left zygomatico-orbital complex 
with metal osteosynthesis. The surgery was performed under general anesthesia (mechanical ventilation with intubation through the mouth) according to standard methods with intraoral access. Fixation of bone fragments, after their repositioning, was performed using a standard titanium mini-plate with microscrews. In the postoperative period, the patient underwent a control CBCT, which showed the presence of displacement of fragments up to $4 \mathrm{~mm}$ (Fig. 2, $\boldsymbol{a}, \boldsymbol{b}$ ), left subtotal hemosinus (Fig. 2, b), as well as postoperative bone defect of the anterior wall of the maxillary sinus. In the postoperative period, the patient complained of nasal breathing disorders, moderate pain and swelling on the operated side.

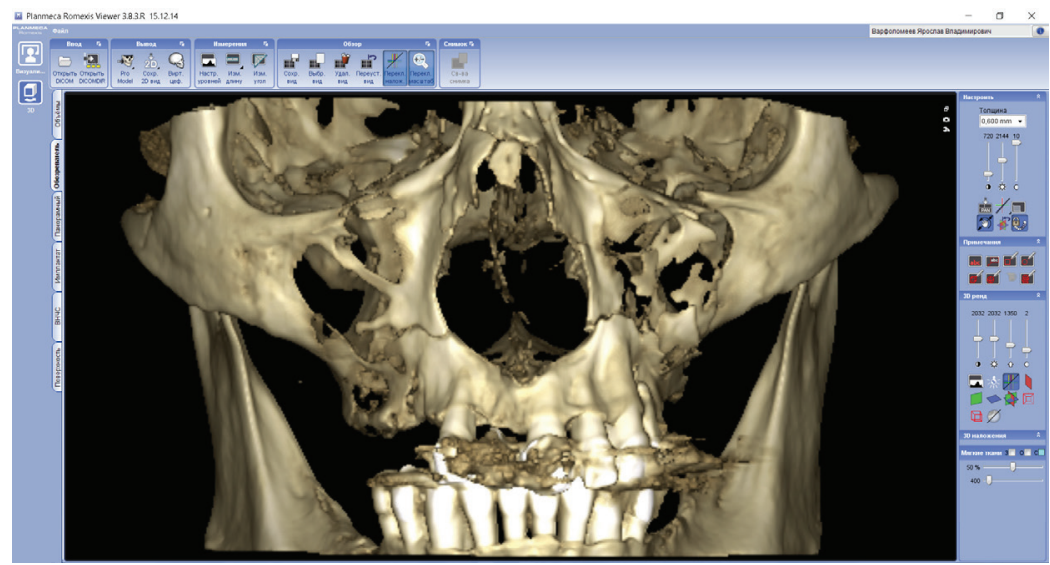

$a$

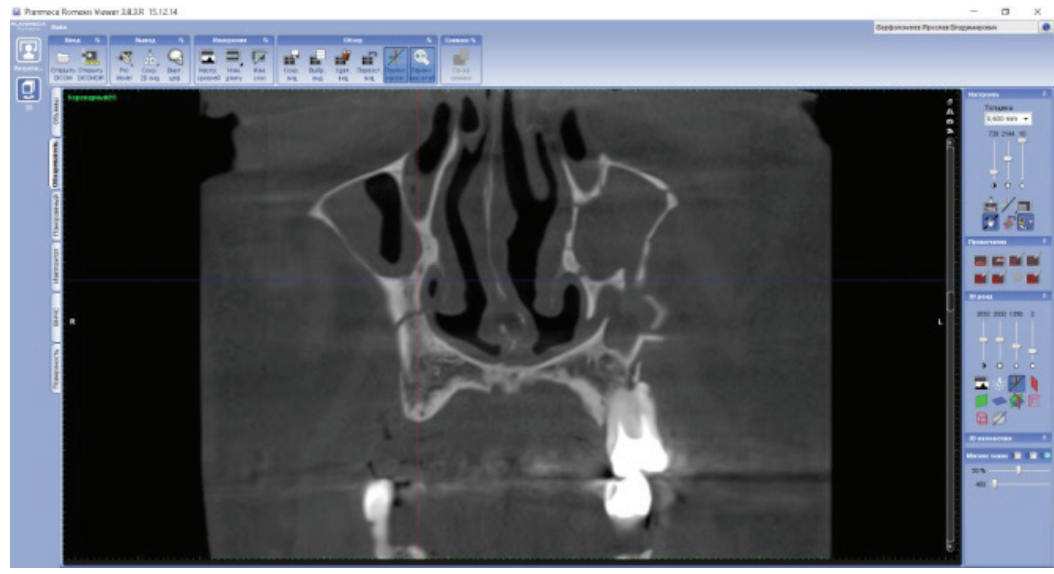

$b$

Fig. 1. CBCT of patient B. before surgery: $a-3 \mathrm{D}$ reconstruction; $b$ - sagittal projection

The postoperative period passed without complications. Sutures were removed on the $10^{\text {th }}$ day after surgery.

Thus, with the help of a standard titanium mini-plate it was not possible to achieve complete restoration of the anatomical shape and integrity of the bones, completely eliminate the displacement of fragments and restore the integrity of the anterior wall of maxillary sinus and eliminate post-traumatic bone defect.

Patient P., 23 years old, went to the department with complaints of facial configuration dislocation on the left side, pain in the middle third of the face on the left side, numbness in the left occipital, buccal areas, the presence of "steps" on the lower eye edge to the left side, nosebleeds after injury on the side of the injury, deterioration of the general condition. According to the patient, he was injured as a result of falling from a height of his own height. After the injury, during the day he appealed for medical help at the Department of Head and Neck Surgery of the Municipal Non-Commercial Enterprise of Kharkiv Regional Council "Regional Clinical Hospital”. 

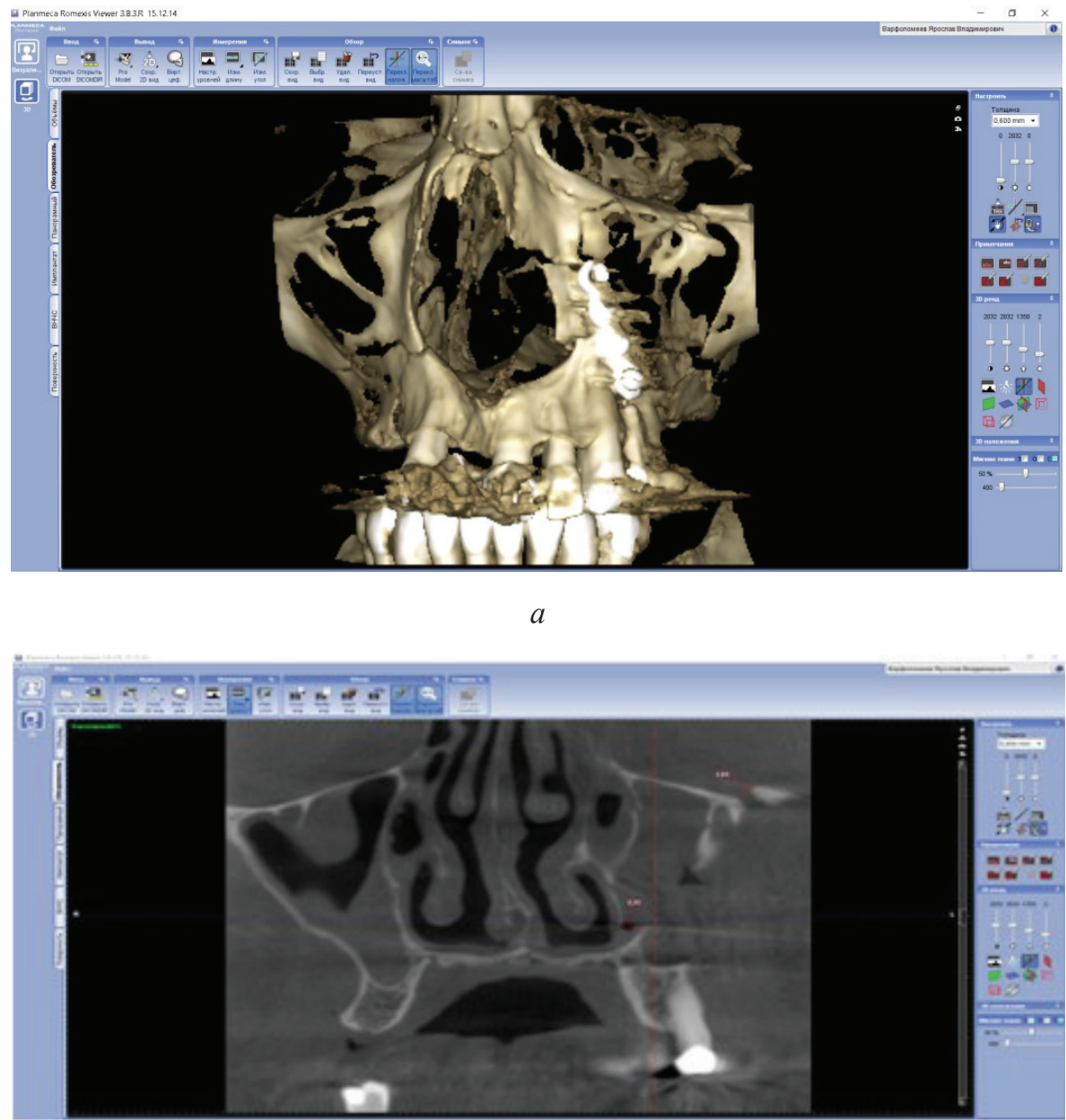

$b$

Fig. 2. Control CBCT of patient $\mathrm{B}$. after surgery: $a-3 \mathrm{D}$ reconstruction; $b$ - sagittal projection

During the examination, the patient underwent $\mathrm{CBCT}$, the results of which were diagnosed as: "Traumatic fracture of the cheekbone on the left side with displacement of fragments" (Fig. 3, a, b).

The displacement of the fragments according to CT was up to $6.64 \mathrm{~mm}$. The patient had a small fragmentary fracture of the anterior wall of the left maxillary sinus with the transition to the lower edge of the left orbit.

The patient underwent repositioning of fragments of the left zygomatico-orbital complex with metal osteosynthesis using an individual 3D-simulated titanium mini-grid.

According to the CBCT, taking into account the location of fractures and their characteristics, 3D-models of the jaw injured area were created, after which a "virtual reposition" and comparison of fragments in the fracture area was performed (Fig. 4, a).

Based on the created virtual model, taking into account traumatic changes and anatomical contours of bones, modeling of individual 3D-mini-grids and endoprostheses (Fig. 4, b) was carried out using computer-aided design systems (CAD/CAM-systems) [24]. The final stage was the printing of individual 3D mini-grids and endoprostheses on a 3D printer SLM 280 HL (SLM Solutions GmbH) according to the method of SLM (Selective Laser Melting) from titanium powder (Fig. $4, c$ ).

The surgery was performed on a patient under general anesthesia (mechanical ventilation with intubation through the mouth) according to standard methods with intraoral access. Fixation of bone fragments was performed using an individual 3D-simulated titanium mini-grid (Fig. 5), which eliminated the bone defect of the anterior wall of the left maxillary sinus. 


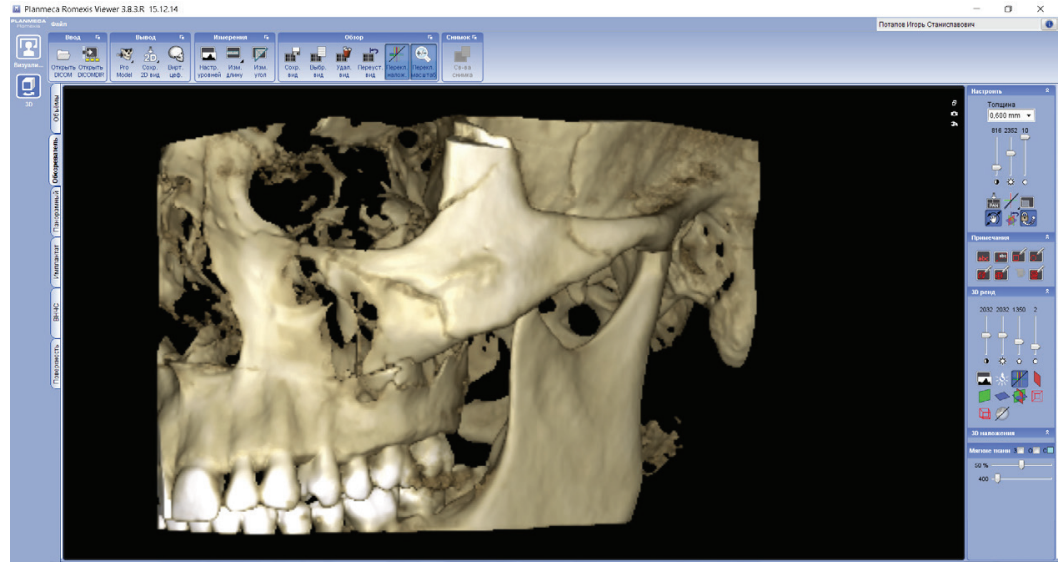

$a$

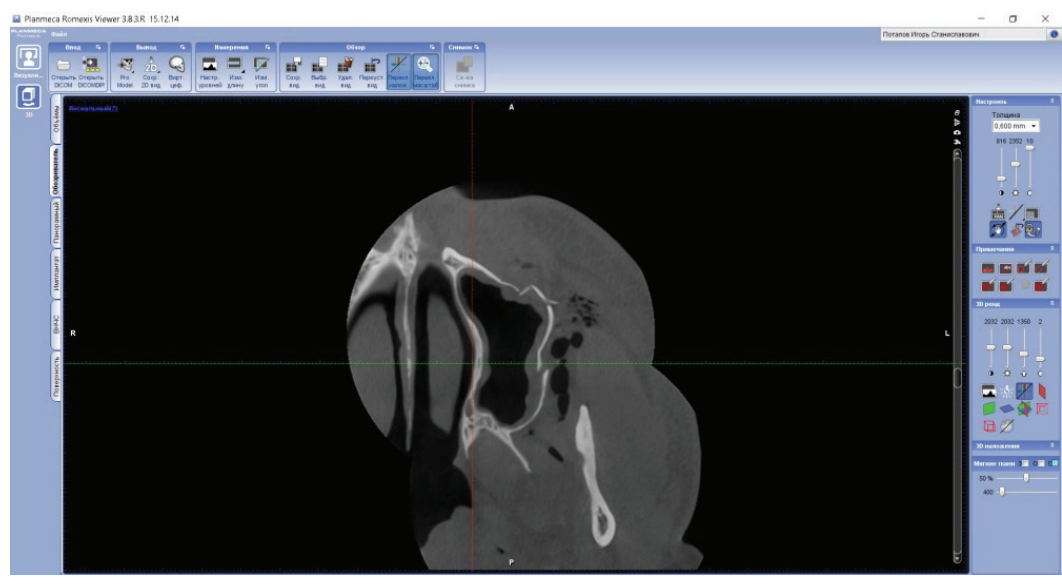

$a$

Fig. 3. CBCT of the patient P. before surgery: $a-3 \mathrm{D}$ reconstruction; $b-$ axial projection

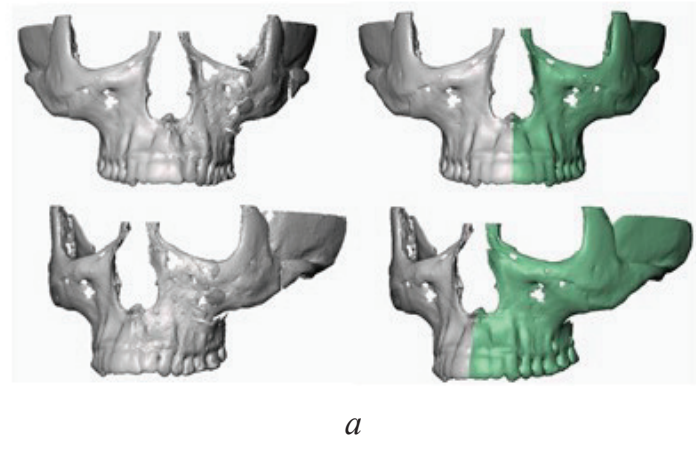

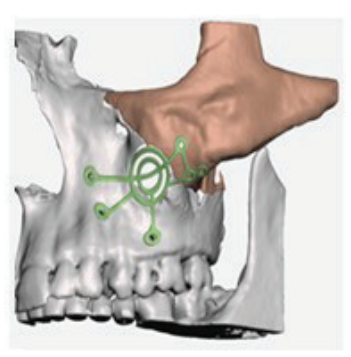

$b$

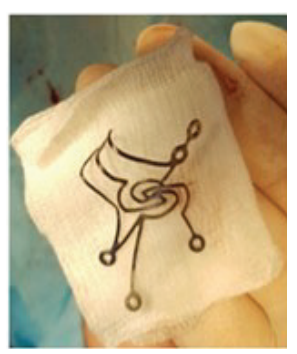

c

Fig. 4. Printing of individual 3D mini-grid: $a$-virtual reposition of fragments in the fracture zone; $b$ - the stage of modeling an individual 3D mini-grid; $c$-individually made 3D-mini-grid 
The surgery was performed on a patient under general anesthesia (mechanical ventilation with intubation through the mouth) according to standard methods with intraoral access. Fixation of bone fragments was performed using an individual 3D-simulated titanium mini-grid (Fig. 5), which eliminated the bone defect of the anterior wall of the left maxillary sinus.

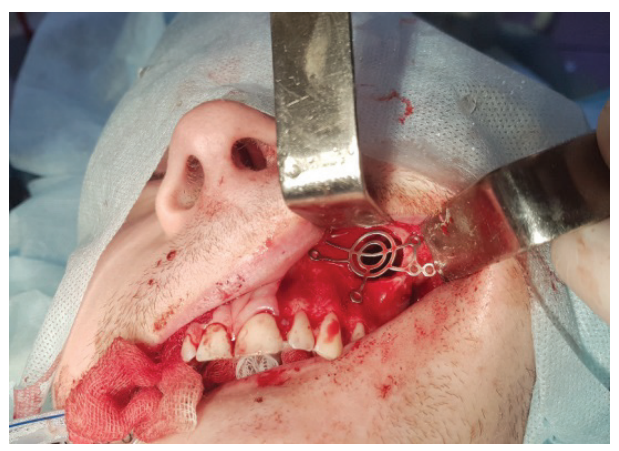

Fig. 5. Fixation of a 3D-simulated individual mini-grid in patient $P$.

In the postoperative period, the patient underwent a control CBCT, which showed complete elimination of the displacement of the fragments (Fig. 6). Hemosinus was absent. Post-traumatic and postoperative defects of the anterior wall of the left maxillary cavity were eliminated with the help of an individual 3D-simulated titanium mini-grid.

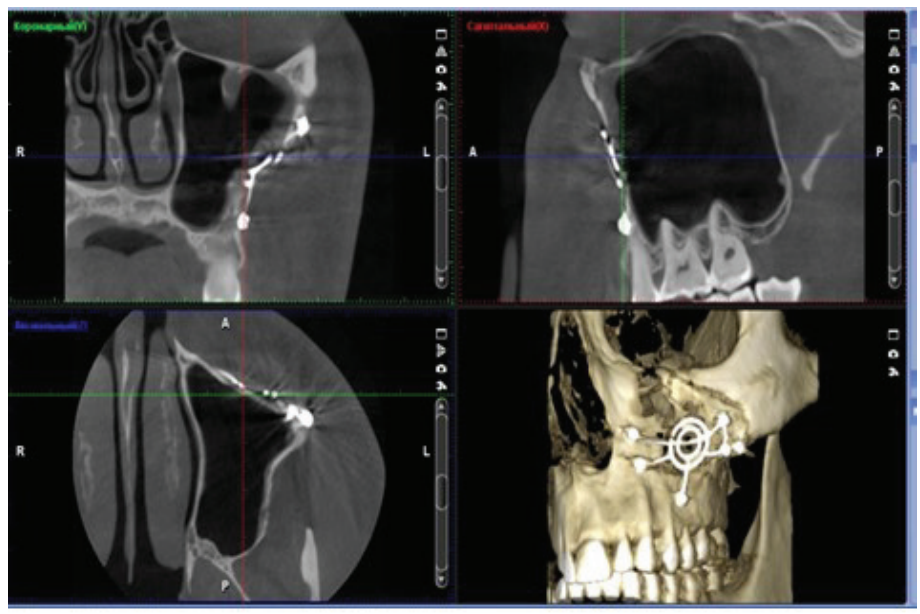

Fig. 6. Control $\mathrm{CBCT}$ of the patient $\mathrm{P}$. after operation: sagittal, transverse, axial projections and 3D-reconstruction

In the postoperative period the patient complained of slight pain and swelling on the operated side. Postoperative supervision of the patient for two years did not reveal any complications, including pathological changes in the maxillary sinus.

\section{Discussion of research results}

Zygomatico-orbital and zygomatic-orbito-maxillary complex play an important role in the formation of the aesthetic zone of the face, its functioning and protection [25].

Fractures of the cheekbone and fractures of the middle face are often observed in clinical practice. Typical clinical signs of these fractures are diplopia, flattening of the face, a symptom of "steps" in the area of the infraorbital rim, impaired occlusion and sensitivity due to injury of the hyoid nerve [26].

The purpose of surgical treatment of fractures of the cheekbone and middle area of the face is to achieve the correct anatomical position of displaced fragments, reduction and closure of bone defects caused by lost or displaced bones, which prevents postoperative complications. Such 
injuries are usually treated by closed repositioning of the fracture without fixation or by open repositioning and internal fixation using titanium mini-plates and grids [27].

Sensitivity disorders are one of the most common postoperative complications in the treatment of fractures. Its recovery after fractures of the face middle area is influenced by many factors, including the method of treatment. Fractures that have been repositioned or fixed inadequately (remaining displacement) can cause compression of the hyoid nerve, leading to persistent impairment of sensitivity [28].

Another possible cause of paresthesia is the formation of scar tissue, which occurs in the presence of bone fissures (defects), occurring due to small fractures of the anterior wall of the maxillary sinus. Scar tissue can form at intervals and cause compression of the occipital nerve, which can lead to impaired sensitivity or mucocele formation [29].

Thus, an important aspect of surgical treatment is the maximum possible closure of bone defects, which prevents postoperative complications after fractures of the middle face [30].

Our research was aimed at comparing the efficiency of using individual 3D simulated titanium mini-plates/grids and standard titanium mini-plates. Before and after treatment, the effectiveness of treatment was evaluated by the values of the displacement of bone fragments and the VAS index, which allowed determining the functional and cosmetic effect of the operation. It was determined that the use of individual 3D simulated titanium mini-plates/grids allowed to obtaining displacements in $85 \%$ of patients not exceeding $3 \mathrm{~mm}$. In $72 \%$ of patients in whom standard titanium mini-plates were used, the displacement after surgery was $3.1-6 \mathrm{~mm}$, which was significantly greater than in the group with individual modeling of structures.

The VAS indices of patients before treatment in the studied groups did not differ significantly. On the 7th day after surgery in the first group (treatment using standard mini-plates) the VAS index equaled $11(7 ; 13)$, which was significantly $(p=0.00147)$ less than before surgery. In the second group (treatment using individual 3D simulated titanium mini-plates/grids), the VAS index was $4(6 ; 8)$, which was significantly ( $p=0.00098)$ less than before surgery. Comparison of VAS indices of the first and the second groups on the 7th day after surgery revealed the presence of significant $(p=0.013)$ differences. VAS in the second group was significantly less than in the first group, which indicated the greater efficiency of individual 3D simulated titanium mini-plates/grids compared to standard titanium mini-plates.

Study limitations. This study has potential limitations: not all patients can receive individualized treatment due to the lack of appropriate material and technical base, modern calculation technologies (CAD/CAM-systems), the possibility of manufacturing individual 3D-simulated titanium mini-plates in many hospitals and in due to their high cost of manufacture.

The prospects of further research are developing a decision support system for physicians to choose the optimal method of treatment of the middle face fractures.

\section{Conclusions}

1. According to the examination of patients before surgery, it was found that the study groups did not differ significantly in terms of treatment, localization of fractures, their number, the amount of displacement of fragments and the VAS index, which allowed comparing treatment results.

2. After surgical treatment using 3D-simulated titanium mini-plates/grids, $85 \%$ of patients in the second group after surgery had no displacement, or it was $1-3 \mathrm{~mm}$. In $72 \%$ of patients in the first group, the displacement was $3.1-6 \mathrm{~mm}$, so it was greater than in the second group in a significant $(p<0.05)$ majority of patients.

3. Before treatment, the score for VAS in the first group of patients equaled $16(13 ; 21)$, in the second - $14(12 ; 19)$. There were no significant differences between the VAS groups before treatment.

4. On the $7^{\text {th }}$ day after surgery first group, the score for VAS was $11(7 ; 13)$, which was significantly ( $p=0.00147$ ) less than before surgery. In the second group, the VAS index equaled 4 $(6 ; 8)$ points, which was significantly $(p=0.00098)$ less than before surgery. Comparison of VAS indexes of the first and second groups on the 7th day after surgery revealed the presence of significant ( $p=0.013$ ) differences. VAS index in the second group was significantly less than in the first group, which indicated the greater efficiency of individual 3D simulated titanium mini-plates/grids compared to standard titanium mini-plates. 


\section{Conflict of interests}

The authors declare that they have no conflicts of interest.

\section{Acknowledgments}

The author expresses his sincere gratitude to the head of the Department of Surgical Dentistry and Maxillofacial Surgery of KhNMU, the initiator and head of this work, Doctor of Medicine, Professor Grigorov S.M., for the opportunity to fulfill it, for assistance in determining the main direction of work and careful guidance.

\section{References}

[1] Juncar, M., Tent, P. A., Juncar, R. I., Harangus, A., Mircea, R. (2021). An epidemiological analysis of maxillofacial fractures: a 10-year cross-sectional cohort retrospective study of 1007 patients. BMC Oral Health, 21 (1). doi: http://doi.org/10.1186/ s12903-021-01503-5

[2] Ahmed, D. R., Dhasarathan, P., Muthusekhar, D. (2020). Incidence and etiology of midface fracture: a retrospective study. Annals of Tropical Medicine and Health, 23, 232-315.

[3] Yu, M., Wang, S.-M. (2021). Anatomy, Head and Neck, Zygomatic. StatPearls. Available at: https://pubmed.ncbi.nlm.nih. gov/31334977/

[4] Louis, M., Agrawal, N., Truong, T. A. (2017). Facial Trauma: Midface Fractures II. Seminars in plastic surgery, 31 (2), 94-99. doi: http://doi.org/10.1055/s-0037-1601373

[5] Hardt, N., Kuttenberger, J. (2010). Mechanisms of craniofacial fractures. Craniofacial Trauma. Springer, Berlin, Heidelberg, 55-61. doi: http://doi.org/10.1007/978-3-540-33041-7_4

[6] Kuzenko, Ye. V., Skydanenko, M. S., Moskalenko, R. A., Lyndin, M. S., Sikora, V. V., Hudymenko, O. O., et. al. (2018) Doslidzhennia zmin u kistkakh pry perelomakh za umov vykorystannia nanomaterialiv dlia metal-osteosyntezu z urakhuvanniam funktsii miazovoho aparatu. Available at: https:/essuir.sumdu.edu.ua/bitstream-download/123456789/73095/1/Kuzenko_1415.pdf

[7] Krause, M., Hümpfner-Hierl, H., Völker, L., Hierl, T., Pausch, N. C. (2017). A new approach to treat bone gaps after midfacial and zygomatic fractures with a collagen membrane. Oral and Maxillofacial Surgery, 21 (4), 439-446. doi: http://doi.org/ 10.1007/s10006-017-0652-z

[8] Panicker, P., Mohan, S., Nallusamy, J., Lakshmi, S., Johny, J., Bhaskaran, M. (2020). Reconstruction of craniofacial bone defects with autologous human bone marrow stem cells and autogenous bone grafts: A case report with review of literature. Journal of Pharmacy And Bioallied Sciences, 12 (5), 394. doi: http://doi.org/10.4103/jpbs.jpbs_116_20

[9] Jensen, S. S., Terheyden, H. (2009). Bone augmentation procedures in localized defects in the alveolar ridge: clinical results with different bone grafts and bone-substitute materials. Database of Abstracts of Reviews of Effects (DARE): Quality-Assessed Reviews. Available at: https://www.ncbi.nlm.nih.gov/books/NBK77628/

[10] Kozlov, V. A., Kagan, I. I., Matchin, A. A., CHemezov, S. V.; Kozlov, V. A., Kagan, I. I. (Eds.) (2014). Operativnaia cheliustno-litsevaia khirurgiia i stomatologiia. Moscow: GEOTAR-MEDIA, 544.

[11] Malanchuk, V. O., Astapenko, O. O. (2014). Rezultaty khirurhichnoho likuvannia khvorykh iz perelomamy ta deformatsiiamy kistok lytsevoho cherepa iz zastosuvanniam riznykh fiksatoriv dlia osteosyntezu. Visnyk stomatolohii, 4, $39-44$.

[12] Gareb, B., Roossien, C. C., van Bakelen, N. B., Verkerke, G. J., Vissink, A., Bos, R. R. M., van Minnen, B. (2020). Comparison of the mechanical properties of biodegradable and titanium osteosynthesis systems used in oral and maxillofacial surgery. Scientific Reports, 10 (1). doi: http://doi.org/10.1038/s41598-020-75299-9

[13] Vares, Ya. E. (2009). Paramedian fractures of the mandible. Modern views on a surgical treatment. Ukrainskyi morfolohichnyi almanakh, 7 (2), 19-21.

[14] Komok, O. A., Malevych, O. Ye., Marikutsa, B. I. (2001). Pat. No. 39746 A UA. Supraosteal plate for osteosynthesis of mandibulary fracture. MPK: A61B 17/58, A61B 17/064. No. 2001010705; declareted: 31.01.2001; published: 15.06.2001, Bul. No. 5.

[15] Timofeev, A. A. (2020). Cheliustno-litsevaia khirurgiia i khirurgicheskaia stomatologiia. Book 1. Kyiv: VSI «Meditsina», 992.

[16] Erol, B., Tanrikulu, R., Görgün, B. (2004). Maxillofacial Fractures. Analysis of demographic distribution and treatment in 2901patients (25-year experience). Journal of Cranio-Maxillofacial Surgery, 32 (5), 308-313. doi: http://doi.org/10.1016/ j.jcms.2004.04.006

[17] Riviș, M., Roi, C., Roi, A., Nica, D., Văleanu, A., Rusu, L.-C. (2020). The Implications of Titanium Alloys Applied in Maxillofacial Osteosynthesis. Applied Sciences, 10 (9), 3203. doi: http://doi.org/10.3390/app10093203

[18] Costan, V. V., Nicolau, A., Sulea, D., Ciofu, M. L., Boișteanu, O., Popescu, E. (2021). The Impact of 3D Technology in Optimizing Midface Fracture Treatment-Focus on the Zygomatic Bone. Journal of Oral and Maxillofacial Surgery, 79 (4), 880-891. doi: http://doi.org/10.1016/j.joms.2020.11.004 
[19] Sikora, M., Chęciński, M., Sielski, M., Chlubek, D. (2020). The Use of 3D Titanium Miniplates in Surgical Treatment of Patients with Condylar Fractures. Journal of Clinical Medicine, 9 (9), 2923. doi: http://doi.org/10.3390/jcm9092923

[20] Gray, R., Gougoutas, A., Nguyen, V., Taylor, J., Bastidas, N. (2017). Use of three-dimensional, CAD/CAM-assisted, virtual surgical simulation and planning in the pediatric craniofacial population. International Journal of Pediatric Otorhinolaryngology, 97, 163-169. doi: http://doi.org/10.1016/j.ijporl.2017.04.004

[21] Vignesh, U., Mehrotra, D., Anand, V., Howlader, D. (2017). Three dimensional reconstruction of late post traumatic orbital wall defects by customized implants using CAD-CAM, 3D stereolithographic models: A case report. Journal of Oral Biology and Craniofacial Research, 7 (3), 212-218. doi: http://doi.org/10.1016/j.jobcr.2017.09.004

[22] Dreizin, D., Nam, A. J., Hirsch, J., Bernstein, M. P. (2018). New and emerging patient-centered CT imaging and image-guided treatment paradigms for maxillofacial trauma. Emergency Radiology, 25 (5), 533-545. doi: http://doi.org/10.1007/ s10140-018-1616-9

[23] Voloshan, O. O., Grigorov, S. M., Demyanyk, D. S. (2020). Development and analysis of diagnostic criteria for creation of an automated computer software for predicting the course and individualizing the treatment of patients with odontogenic maxillary sinusitis. Wiadomości Lekarskie, 73 (4), 767-772. doi: http://doi.org/10.36740/wlek202004127

[24] Vasylenko, I. V., Hryhorov, S. M., Khudyk, A. K. (2021). Pat. No. 145754 UA. Sposib likuvannia travmatychnykh perelomiv kistok shchelepno-lytsevoi dilianky u doroslykh z vykorystanniam nakistkovoho osteosyntezu 3D modelovanymy tytanovymy miniplastynamy. MPK: A61B 17/58 (2006.01), A61C 3/00, A61C 8/00, A61C 11/00. No. a201807783; declareted: 11.07.2018; published: 06.01.2021, Bul. No. 1.

[25] Moreira Marinho, R. O., Freire-Maia, B. (2013). Management of Fractures of the Zygomaticomaxillary Complex. Oral and Maxillofacial Surgery Clinics of North America, 25 (4), 617-636. doi: http://doi.org/10.1016/j.coms.2013.07.011

[26] Das, A. K., Bandopadhyay, M., Chattopadhyay, A., Biswas, S., Saha, A., Balkrishna, U. M., Nair, V. (2015). Clinical evaluation of neurosensory changes in the infraorbital nerve following surgical management of zygomatico-maxillary complex fractures. Journal of Clinical and Diagnostic Research, 9, 54-58. doi: http://doi.org/10.7860/jcdr/2015/16511.7008

[27] Lee, E., Mohan, K., Koshy, J., Hollier, L. (2010). Optimizing the Surgical Management of Zygomaticomaxillary Complex Fractures. Seminars in Plastic Surgery, 24 (4), 389-397. doi: http://doi.org/10.1055/s-0030-1269768

[28] Ellis, E., Perez, D. (2014). An Algorithm for the Treatment of Isolated Zygomatico-Orbital Fractures. Journal of Oral and Maxillofacial Surgery, 72 (10), 1975-1983. doi: http://doi.org/10.1016/j.joms.2014.04.015

[29] Kotrashetti, S. M., Kale, T. P., Bhandage, S., Kumar, A. (2015). Infraorbital nerve transpositioning into orbital floor: a modified technique to minimize nerve injury following zygomaticomaxillary complex fractures. Journal of the Korean Association of Oral and Maxillofacial Surgeons, 41 (2), 74-77. doi: http://doi.org/10.5125/jkaoms.2015.41.2.74

[30] Yao, B., He, Y., Jie, B., Wang, J., An, J., Guo, C., Zhang, Y. (2019). Reconstruction of Bilateral Post-Traumatic Midfacial Defects Assisted by Three-Dimensional Craniomaxillofacial Data in Normal Chinese people - A Preliminary Study. Journal of Oral and Maxillofacial Surgery, 77 (11), 2302.e1-2302.e13. doi: http://doi.org/10.1016/j.joms.2019.04.030 